\title{
ANALISIS PROFIL DASAR SALURAN UNTUK MENGURANGI KECEPATAN ALIRAN PADA PENGALIHAN SUNGAI
}

\author{
Dinar DA Putranto ${ }^{1)^{*}}$, Agus L Yuono ${ }^{2)}$, dan MA Muzakki Effendi ${ }^{3)}$ \\ ${ }^{1,2)}$ Jurusan Teknik Sipil dan Perencanaan FT UNSRI, Jl. Raya Prabumulih - Km 32 Indralaya, Ogan Ilir, Sumsel \\ 3) Alumni Program Studi Teknik Sipil, FT UNSRI
}

\section{Abstract}

In coal mining activities, it is often found that coal reserves are located in layers far from the land surface, and can be located far below the riverbed. In such conditions, the choice that is often taken is to move the river flow. Displacement of river flows in accordance with the regulations allowed has its own challenges to minimize the risks that will occur to the environment. The aim of the study is to design the basis of a new channel to reduce the speed of the river flow, so that the function and sustainability of river use as an ecological function is not disturbed. The method used is to analyze the origin of the river channel discharge and design the dimensions of the diversion river channel. The results obtained, with forecasts of a 50 year return peak flood period of $104.17 \mathrm{~m}^{3} / \mathrm{sec}$ and with a divergence in the elevation of the diverting river channel of $18.9 \mathrm{~m}$ between the planned upstream and downstream along the $6,212.7 \mathrm{~m}$, then to avoid massive scouring at channel base, a maximum flow rate of $10 \mathrm{~m} / \mathrm{sec}$ and a minimum of $0.8 \mathrm{~m} / \mathrm{sec}$ with a channel bottom of $0.0005 \%$ is recommended. For this reason the base profile of the canal is trapped at a distance of $500 \mathrm{~m}$, with an elevation difference of $0.25 \mathrm{~m}$. To maintain ecological sustainability, the dimension of the diversion river channel is maintained the same as the original river, $\mathrm{b}=8 \mathrm{~m}, \mathrm{H}=3.5 \mathrm{~m}$, and $\mathrm{H}: \mathrm{V}=1.5: 1$.

Key Words: discharge, environmental risk, minimize risk, river channel

\section{PENDAHULUAN}

Selama puluhan tahun, penduduk daerah pedesaan telah menggunakan saluran air untuk berbagai keperluan hidupnya, termasuk penyediaan air bersih. Perkembangan otonomi daerah, telah mendorong pemerintah daerah meningkatkan pendapatan asli daerah (PAD) melalui pemberian ijin usaha termasuk ijin kuasa penambangan. Eksploitasi ekonomi sepanjang daerah aliran sungai melalui penambangan batubara berlangsung sangat cepat sesuai ijin usaha yang telah diberikan. Salah satu wilayah di Sumatera Selatan yang mempunyai potensi tambang batubara dengan cadangan yang cukup besar adalah Kabupaten Lahat. Namun dalam beberapa tahun terakhir, persaingan antara pertumbuhan ekonomi dan ekosistem sungai telah memicu serangkaian krisis lingkungan di Kabupaten Lahat. Peristiwa terakhir adalah banjir di Kabupaten Lahat pada bulan Januari 2020, yang menyebabkan beberapa desa tergenang, tanah longsor dan menelan banyak kerugian materiil dan non materiil.

Pernambangan batubara adalah salah satu bisnis padat teknologi, modal dan resiko serta bisnis menggiurkan dengan keuntungan yang besar jika dapat meminimalkan resiko (Riswan \& Saismana, 2016). Salah satu resiko adalah lapisan atau cadangan batubara yang akan ditambang terletak jauh dari permukaan atau berada di bawah sungai. Pada kasus demikian, pilihan yang banyak diambil adalah memindahkan aliran sungai asli, agar cadangan batubara dibawahnya dapat diekploitasi.

Sesuai dengan Peraturan Menteri Pekerjaan Umum dan Perumahan Rakyat Republik Indonesia No 26/PRT/M/2015 tentang pengalihan alur sungai dan/atau pemanfaatan ruas bekas sungai, Pasal 1 ayat 3 , yang dimaksud dengan pengalihan alur sungai adalah kegiatan mengalihkan alur sungai dengan cara membangun alur sungai baru atau meningkatkan kapasitas alur sungai yang ada yang mengakibatkan terbentuknya alur sungai baru atau berpindahnya aliran sungai lama (Kementerian PUPR, 2015).

Kecamatan Merapi Barat yang terletak di Kabupaten Lahat, Provinsi Sumatera Selatan mempunyai cadangan batubara yang penyebarannya banyak menerus ke bawah aliran sungai. Dibawah aliran sungai tersebut terdapat jutaan ton potensi batubara. Salah satu Daerah Aliran Sungai (DAS) yang sudah mengalami penurunan kualitas akaibat kegiatan penambangan batubara adalah DAS Lematang (Putranto dkk., 2017), disebabkan banyaknya ijin-ijin kuasa penambangan yang diberikan di daerah tersebut.

Dalam suatu kajian teknis untuk mengoptimalkan kegiatan penambangan batubara di Kecamatan Merapi, Kabupaten Lahat, dilakukan analisis teknis pengalihan sungai pada sungai Kungkilan (1.763 m), Sungai Nipe (1.082 m) dan 
Sungai Tabuhan $(1.829 \mathrm{~m})$. Ketiga sungai tersebut bermuara pada Sungai Lematang. Untuk melihat apakah sudah sesuai dengan ketentuan teknis sesuai Peraturan Menteri Pekerjaan Umum dan perumahan Rakyat Republik Indonesia No 26/PRT/M/2015, bab 3 pasal 5 ayat 4 tentang : (a) pemeriksaan hitungan luas alur sungai lama yang akan dialihkan dan luas rencana alur sungai baru; (b) pemeriksaan terhadap hitungan pengaruh pengalihan alur sungai terhadap muka air banjir di hilir lokasi pengalihan dan penurunan dasar sungai di hulu lokasi pengalihan, maka dilakukan kajian teknis untuk menganalisis potensi dan kesesuaian pengalihan alur sungai agar dikemudian hari tidak terjadi permasalahan yang akan mengganggu lingkungan sungai di daerah hilirnya.

Tujuan dari studi pengalihan alur sungai Kungkilan, sungai Nipe dan Sungai Tabuhan adalah untuk memperoleh hasil analisis kapasitas sungai eksisting sebelum dialihkan alurnya dan menganalisis kapasitas saluran sungai pengalihan. Sedangkan tujuan khusus dari studi ini, adalah: (a) Menganalisis besarnya debit saluran pada masingmasing sungai yang akan dialihkan sebagai akibat dari besarnya debit DAS disekitarnya; (b) Menganalisis kapasitas saluran baru untuk pengalihan sungai, ketinggian rencana, dan penampang saluran rencana.
Sasaran yang ingin dicapai melalui studi ini adalah diketahuinya kapasitas debit saluran eksisting untuk merencanakan debit dan kapasitas pengalihan sungai yang sesuai, penampang sungai, kemiringan dan kecepatan aliran sungai pengalihan, yang diharapkan tidak mengganggu ekologi DAS.

\section{METODOLOGI}

Dalam melaksanakan analisa teknis pengalihan sungai Kungkilan, sungai Nipe dan sungai Tabuhan, dilakukan analisis debit limpasan air permukaan pada daerah aliran sungai menggunakan analisis DAS (Purwitaningsih \& Pamungkas, 2017) dan survei data primer yaitu pengukuran lebar saluran sungai eksisting, pengukuran kecepatan aliran serta pengukuran melintang sepanjang sungai eksisting yang direncanakan untuk dilakukan analisis dengan menggunakan pendekatan analisis hidrologi, analisis banjir rencana, rencana debit dan dimensi saluran (Yuono dkk., 2020).

\section{Wilayah studi}

Wilayah studi merupakan bagian dari sub DAS Lematang Hulu, yang terletak antara $103^{\circ} 39^{\prime}$ $34,92^{\prime \prime}-103^{\circ} 43^{\prime}$ 41,16" BT dan antara $3^{\circ} 44^{\prime}$ 24,72 " - $3^{\circ} 48^{\prime} 47,88^{\prime \prime}$ LS dengan luas keseluruhan DAS wilayah studi adalah 29,643 $\mathrm{Km}^{2}$, dimana sungai Kungkilan, sungai Nipe, dan sungai Tabuhan merupakan bagian sub DAS tersebut.

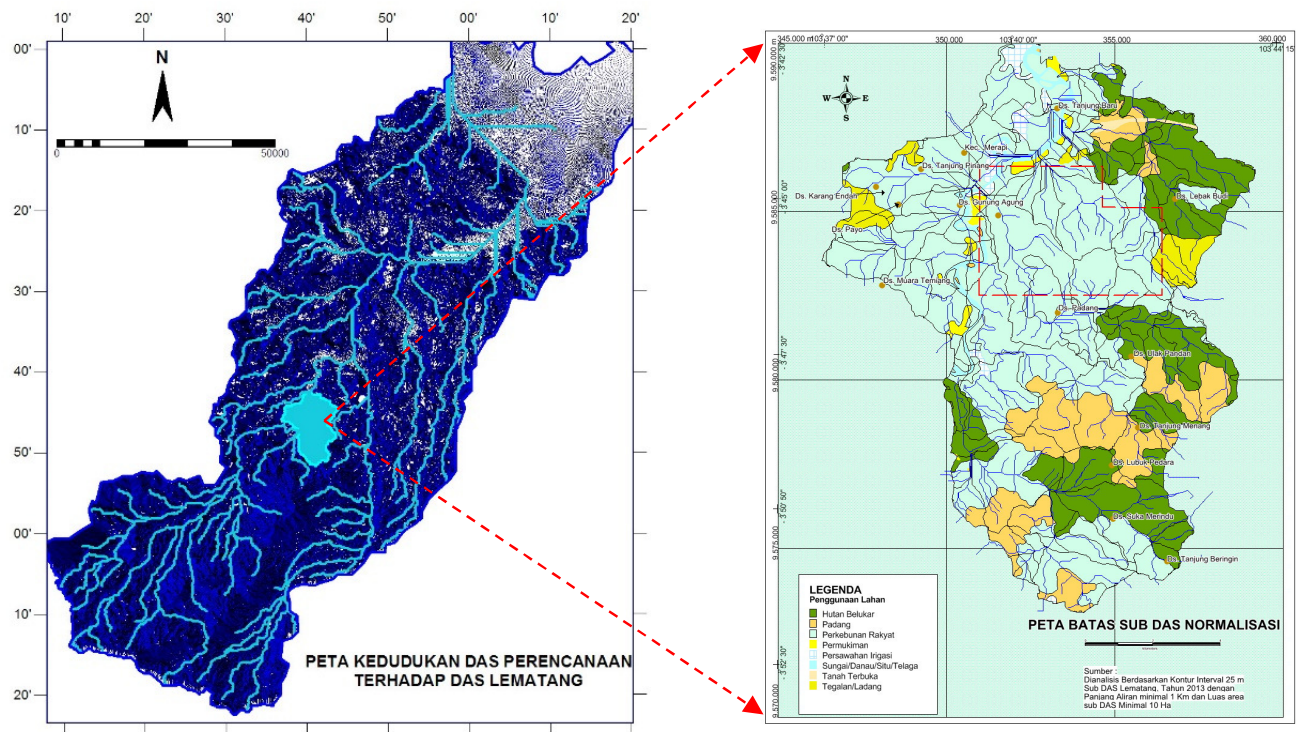

Gambar 1. Kedudukan Sub DAS Kungkilan, Sub DAS Nipe dan Sub DAS Tabuhan pada Sub DAS Lematang

\section{Metode penelitian}

Ada beberapa tahapan yang digunakan dalam menyelesaikan penelitian ini, yaitu analisis topografi wilayah, untuk memperoleh kondisi kemiringan saluran, lebar saluran, dan kecepatan arus, yang akan digunakan untuk analisis kapasitas saluran sungai lama dan kondisi lingkungan DAS untuk memprediksi besarnya total aliran yang masuk kedalam tiga sungai yang menjadi wilayah studi. Analisis dilakukan menggunakan data primer hasil pengukuran langsung dilapangan dan analisis karakteristik DAS menggunakan pendekatan spasial 


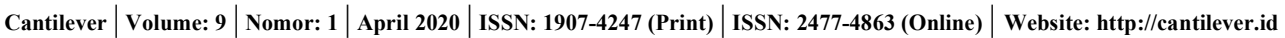
Dinar DA Putranto, dkk. / Analisis Profil Dasar Saluran Baru untuk Mengurangi Kecepatan Aliran pada Pengalihan Sungai

berdasarkan citra satelit wilayah penelitian, peta tematik tanah, dan pengukuran kecepatan aliran (Sarino dkk., 2019) .

Analisis hidrologi dan hidrolika saluran, dilakukan untuk meprediksi besarnya debit sungai, kecepatan aliran dan kapasitas saluran. Analisis aliran dilakukan menggunakan pemodelan $H E C$ $R A S$, untuk menirukan geometri rencana saluran baru, hidrolika sungai, karakteristik profil muka air, dan penentuan dimensi sungai pengalihan (Kurniawan dkk., 2020).

Secara teknis, langkah-langkah penyelesaian penelitian secara diagramatis, dapat dilihat pada Gambar 2 berikut,

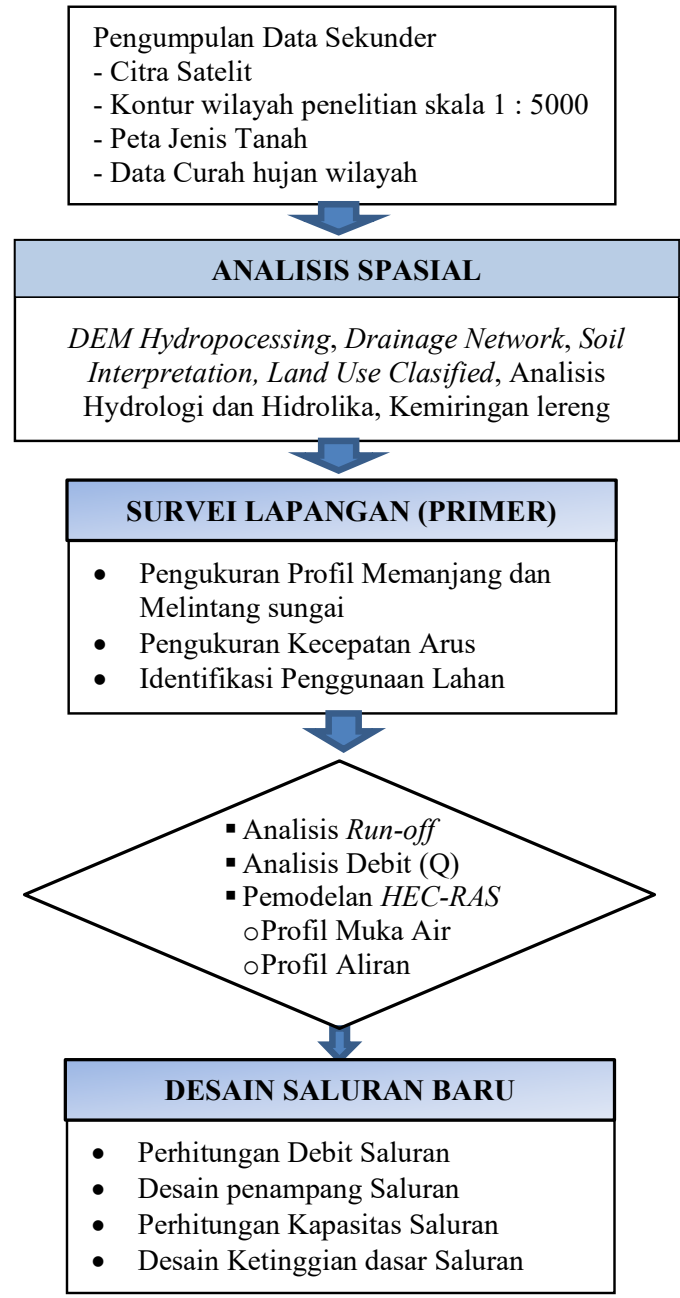

Gambar 2. Diagram Alir Penelitian

\section{HASIL DAN PEMBAHASAN}

Untuk memperoleh kondisi wilayah sub DAS yang meliputi chatment area wilayah masingmasing sub DAS, kemiringan lereng, panjang lereng, panjang saluran, outlet dan inlet, serta area masing-masing sub DAS, dilakukan analisis $D E M$ Hydroprocessing (Putranto dkk., 2015). Analisis DEM Hydroprocessing dilakukan dengan menggunakan perangkat lunak ILWIS 3,8, dengan menganalisis data kontur ketinggian wilayah penelitian.

\section{Karakteristik sub DAS eksisting}

Berdasarkan analisis data ketinggian menggunakan teknik DEM hydroprocessing (lihat Gambar 3 dan Tabel 1), diperoleh luas area sub DAS Kungkilan sebesar 1.776, $36 \mathrm{Ha}$, dengan ketinggian hulu sungai (inlet) 83,7 m dpl. Sementara elevasi outlet sub DAS Kungkilan (bagian hilir) adalah pada ketinggian 64,6 m dpl, dengan luas sub sistem sungai yang mempengaruhi seluas 268,32 Ha. Kemiringan dasar saluran dari inlet di daerah hulu kearah outlet di daerah hilir adalah sebesar $0,39 \%$. Kemiringan ini cenderung sangat landai, dan akan mengganggu aliran material yang di bawa, sehingga diperkirakan akan ditemui banyaknya sedimentasi yang diendapkan pada beberapa titik aliran sungai, terutama pada daerah belokan.

Sementara pada sungai Nipe, luas area sub sistem sungai Nipe meliputi luasan sebesar 379,95 Ha dengan elevasi dasar saluran inlet bagian hulu sebesar 94,5 m dpl. Sementara elevasi dasar saluran pada Outlet di bagian hilir adalah $57,48 \mathrm{~m}$ dpl (lihat Tabel 1). Dengan luas daerah pengaliran yang akan mempengaruhi debit pada Outlet sungai Nipe dibagian hilir seluas 38,08 Ha. Kemiringan dasar saluran dari hulu daerah pengaliran sungai Nipe ke hilir outlet sungai adalah 1,86\% dengan total panjang aliran $2.773,4 \mathrm{~m}$.

Dari data pada Tabel 1, hasil analisis menunjukkan, bahwa ketinggian hulu daerah pengaliran sungai Tabuhan yang akan mempengaruhi debit (Q) pada daerah hilir pengalihan sungai Tabuhan adalah sebesar $100 \mathrm{~m}$ dpl, dengan total panjang aliran sungai sub sistem sungai Tabuhan adalah sepanjang 1.165,7 $\mathrm{m}$ dengan luas daerah pengaliran yang akan mempengaruhi debit (Q) pada inlet pengalihan sungai Tabuhan adalah seluas 108,08 Ha. Sementara hilir sungai pengalihan mempunyai ketinggian 91,1 m dpl dengan luas sub sistem sungai yang mempengaruhi outlet pengalihan sungai Tabuhan adalah seluas 267,65 Ha. Kemiringan dasar saluran dari daerah hulu sub system sungai Tabuhan adalah sebesar 0,87 $\%$ untuk panjang sungai $1.165,7 \mathrm{~m}$.

Dengan kondisi panjang sungai pengalihan, lebar dasar saluran dan luas daerah pengaliran untuk masing-masing sungai yang akan dialihkan, yang perlu diperhatikan adalah kemiringan dasar sungai pengalihan (rencana). Karena perbedaan elevasi yang terlalu tinggi akan menyebabkan besarnya sedimentasi akibat penggerusan dasar dan dinding saluran, sepanjang saluran baru pengalihan sungai.

Sungai Lematang bagian hulu, dengan anak sungainya yang mengalir dari semua arah ke satu 
saluran pelepasan di Sungai lematang mempunyai pola aliran dendritik. Aliran denditrik, biasanya terjadi pada daerah yang mempunyai perbedaan topografi sangat besar, sehingga aliran mengalir melalui lereng-lereng bukit.

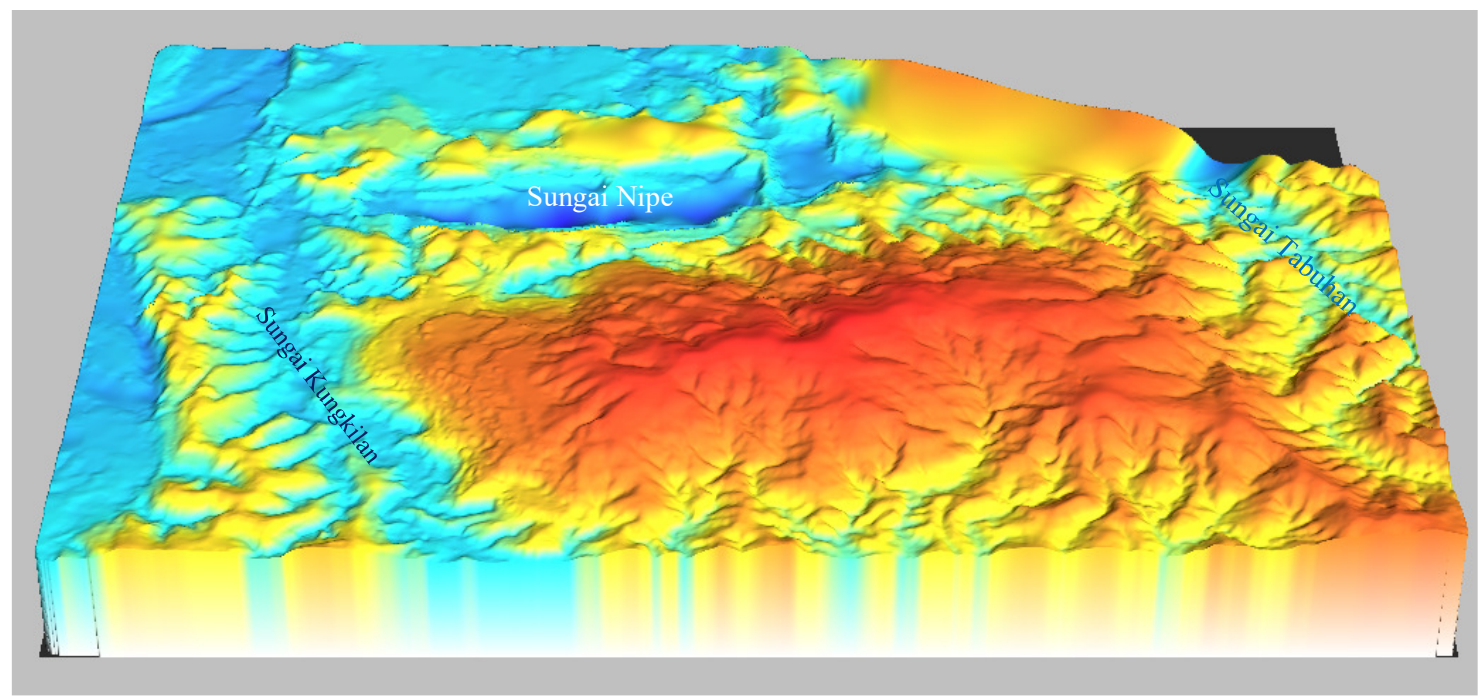

Gambar 3. Digital Elevasi Model (DEM) sub sistem sungai Kungkilan, Nipe dan Tabuhan

Tabel 1. Koordinat inlet, outlet, ketinggian, panjang sungai dan kemiringan sungai eksisting hasil Ekstraksi DEM Hydroprocessing

\begin{tabular}{|c|c|c|c|c|c|c|c|c|c|}
\hline No & $\begin{array}{l}\text { Koordinat Inlet } \\
(\mathrm{m})\end{array}$ & $\begin{array}{l}\text { Elevasi } \\
\text { Inlet }\end{array}$ & $\begin{array}{c}\text { Koordinat_Outlet } \\
(\mathrm{m})\end{array}$ & $\begin{array}{c}\text { Elevasi } \\
\text { Outlet }\end{array}$ & $\begin{array}{l}\Delta \mathrm{H} \\
(\mathrm{m})\end{array}$ & $\begin{array}{l}\text { Panjang } \\
(\mathrm{m})\end{array}$ & $\begin{array}{l}\text { Jarak (m) } \\
\text { Langsung }\end{array}$ & $\begin{array}{c}\text { Kemiringan } \\
\text { DAS }(\%)\end{array}$ & $\begin{array}{l}\text { Slope } \\
\text { Drain }\end{array}$ \\
\hline Nipai & $(353.485 ; 9.584 .523)$ & 94,5 & $(352.945 ; 9.586 .423)$ & 57,8 & 36,7 & $2.773,0$ & $1.975,2$ & 1,32 & 1,86 \\
\hline Tabuhan & $(356.685 ; 9.583 .503)$ & 100,0 & $(356.165 ; 9.584 .383)$ & 91,1 & 8,9 & $1.165,7$ & $1.022,2$ & 0,76 & 0,87 \\
\hline Kungkilan & $(353.805 ; 9.582 .003)$ & 83,7 & $(350.845 ; 9.585 .803)$ & 64,8 & 18,9 & $6.212,7$ & $4.816,8$ & 0,30 & 0,39 \\
\hline
\end{tabular}

Luas Chatment Area, kemiringan dan panjang sungai pengalihan (saluran pengalihan)

Dari Gambar 4 dan Tabel 2, di bawah dapat dijelaskan sebagai berikut : Sub sistem sungai yang paling luas yang akan mempengaruhi debit pada inlet sungai pengalihan adalah sungai Kungkilan, seluas 17,76 Ha. Sementara luas sub sistem sungai yang akan mempengaruhi inlet pada saluran pengalihan sungai Nipai adalah sebesar 3,79 Ha. Dan luas sub sistem sungai yang akan mempengaruhi debit pada inlet saluran pengalihan sungai Tabuhan adalah seluas 1,081 Ha. Namun pelepasan atau Outlet saluran baru sungai Tabuhan tidak langsung dibuang ke sungai Lematang, namun kearah sungai bagian utara.

Panjang sungai utama yang mempengaruhi debit inlet pada saluran pengalihan sungai Kungkilan adalah sepanjang 9,537 Km. Sementara panjang sungai utama yang mempengaruhi pengalihan sungai Nipai adalah sepanjang $3,298 \mathrm{Km}$ dan pengalihan sungai Tabuhan sepanjang 2,012 Km.

Dengan kemiringan lereng lebih dari $8 \%$ untuk sub sistem sungai Nipe dan kemiringan lereng lebih dari $30 \%$ untuk sungai Kungkilan, maka perlu diperhatikan rencana debit inlet dan Outlet pada ke dua pengalihan sungai tersebut. Dengan kemiringan sebesar tersebut di atas, maka kemungkinan akan terjadi pengendapan sedimen pada daerah hilirnya, yaitu wilayah pertemuan antara sungai-sungai pengalihan dengan sungai induknya. Sungai utama akan terdesak oleh anak sungai hasil pengalihan sungai dan bentuk pertemuannya akan bergeser ke arah hulu. Oleh karena itu arus anak sungai akan memberikan pengaruh yang kurang menguntungkan bagi bangunan sungai yang terdapat disebelah hilir pertemuan yang tidak deras alurnya. Lebar sungai utama pada pertemuan dengan anak sungai cenderung akan bertambah, sehingga sering akan terbentuk gosong-gosong pasir dan merubah arah arus sungai. Atas dasar tersebut, maka pada daerah pertemuan, perlu dilakukan perencanaan :

a. Pada pertemuan dua buah sungai yang rezimnya berlainan, maka pada kedua sungai perlu diadakan pengendalian kecepatan arus, agar rezimnya menjadi sama

b. Pada lokasi pertemuan dua buah sungai diusahakan supaya formasi pertemuannya membentuk garis singgung, bukan tegak lurus dengan sungai pertemuannya. 


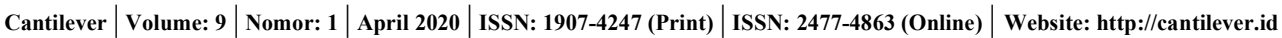
Dinar DA Putranto, dkk. / Analisis Profil Dasar Saluran Baru untuk Mengurangi Kecepatan Aliran pada Pengalihan Sungai

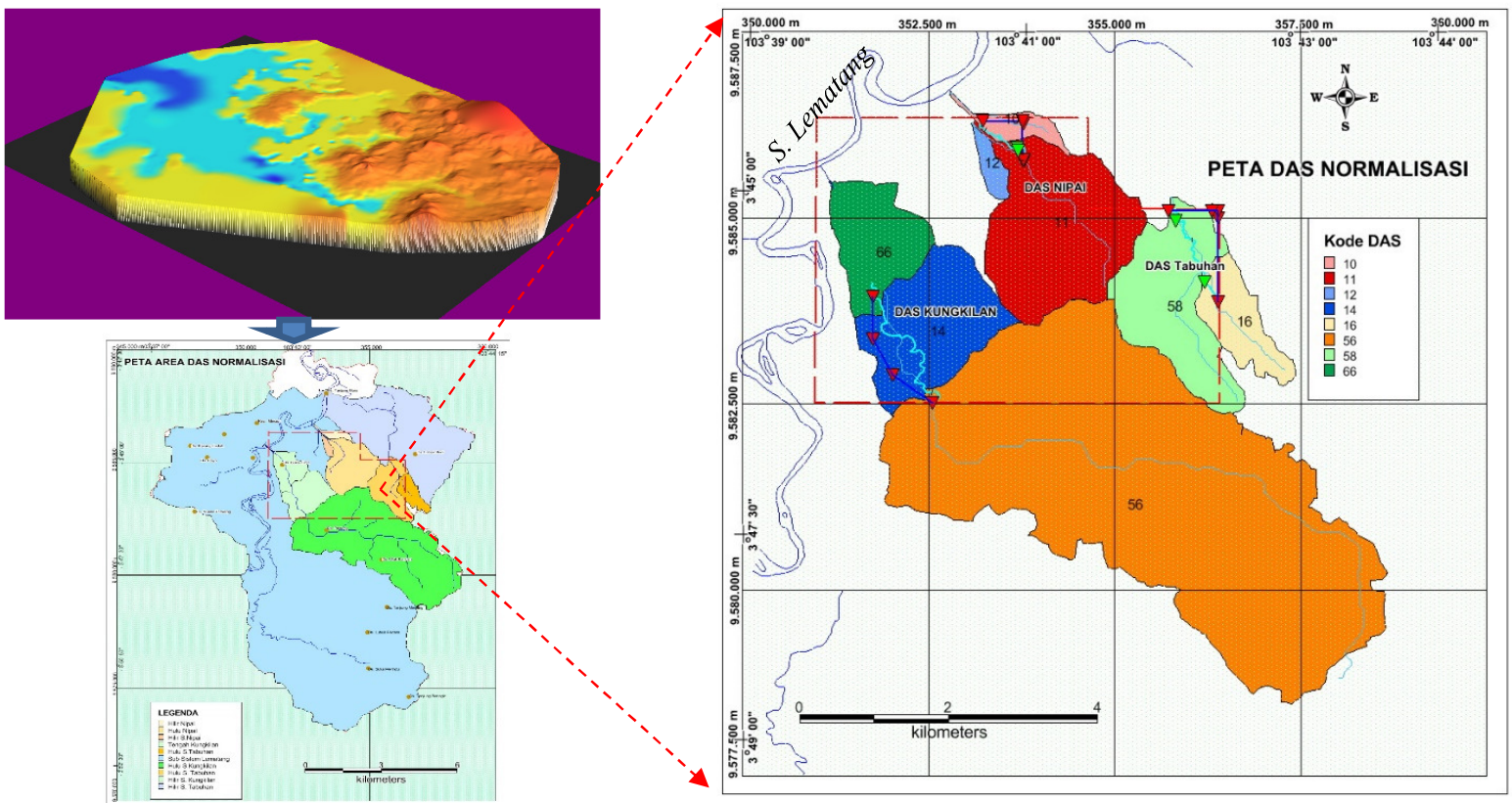

Gambar 4. Extract batas pola pengaliran sub sistem sungai Kungkilan, Tabuhan dan Nipe yang mempengaruhi debit saluran baru

Tabel 2. Panjang dan kemiringan sungai sub sistem sungai yang akan mempengaruhi debit aliran sungai rencana pengalihan

\begin{tabular}{cccccccccc}
\hline $\begin{array}{c}\text { Kode } \\
\text { DAS }\end{array}$ & $\begin{array}{l}\text { Elev_ups } \\
\text { treem }\end{array}$ & $\begin{array}{l}\text { Down } \\
\text { Stream }\end{array}$ & $\begin{array}{l}\text { Beda } \\
\text { Elevasi }\end{array}$ & $\begin{array}{l}\text { Panjang } \\
(\mathrm{m})\end{array}$ & $\begin{array}{l}\text { Jarak } \\
\text { Langsung }\end{array}$ & $\begin{array}{l}\text { Slope } \\
\text { Along }\end{array}$ & $\begin{array}{l}\text { Slope } \\
\text { Along }\end{array}$ & $\begin{array}{l}\text { Slope } \\
\text { Drainase }\end{array}$ & $\begin{array}{l}\text { Slope } \\
\text { Drainase }\end{array}$ \\
\hline 16 & 119,9 & 91,1 & 28,8 & $2.012,8$ & $1.808,5$ & 1,43 & 0,820 & 1,59 & 0,912 \\
\hline 11 & 386,9 & 290,9 & 96,0 & $3.298,6$ & $2.902,3$ & 9,14 & 5,228 & 10,82 & 6,184 \\
\hline 58 & 495,8 & 456,5 & 39,3 & $3.417,8$ & $3.177,7$ & 6,34 & 3,638 & 6,78 & 3,888 \\
\hline 56 & $2.497,2$ & $2.249,8$ & 247,4 & $9.537,0$ & $8.746,6$ & 39,80 & 22,704 & 45,92 & 26,153 \\
\hline 14 & 153,0 & 147,5 & 5,5 & $1.575,4$ & $1.346,1$ & 0,62 & 0,355 & 0,75 & 0,429 \\
\hline 66 & 83,7 & 64,8 & 18,9 & $6.212,7$ & $4.816,8$ & 0,30 & 0,174 & 0,39 & 0,225 \\
\hline 10 & 75,0 & 52,1 & 22,9 & $1.763,7$ & $1.523,2$ & 1,30 & 0,744 & 1,50 & 0,861 \\
\hline 12 & 74,0 & 61,4 & 12,6 & 820,8 & 760,3 & 1,54 & 0,879 & 1,66 & 0,949 \\
\hline \multicolumn{7}{r}{ Parameter Sub DAS Tabuhan } \\
\hline \multicolumn{7}{l}{ Parameter Sub DAS Nipe } & Parameter Sub DAS Kungkilan
\end{tabular}

\section{Analisis hidrologi}

Data hujan yang digunakan dalam analisis ini adalah data hujan dari stasiun penakar hujan Muara Enim dan Pandan Enim. Data hujan dari ke dua stasiun tersebut berupa data hujan harian selama 17 tahun (dari tahun 1994 sampai dengan tahun 2010). Terhadap data hujan tersebut dilakukan analisis frekuensi curah hujan untuk memperoleh curah hujan dengan periode ulang 2, 5, 10, 25, 50 dan 100 tahun. Pada analisis ini digunakan metode (Wilken dkk., 2018): (1) Distribusi Normal; (2) Distribusi Log Normal 2 parameter; (3) Distribusi Pearson Type III; (4) Distribusi Log Pearson Type III; (5) Distribusi Gumbel.

Berdasarkan data yang ada, rata-rata hujan harian maksimum wilayah penelitian selama tujuh belas tahun terakhir (1994-2010) dapat dilihat pada grafik Gambar 5. Sedangkan perhitungan analisis curah hujan untuk data harian rata-rata maksimum dengan menggunakan kelima metode tersebut diperlihatkan dalam Tabel 3.

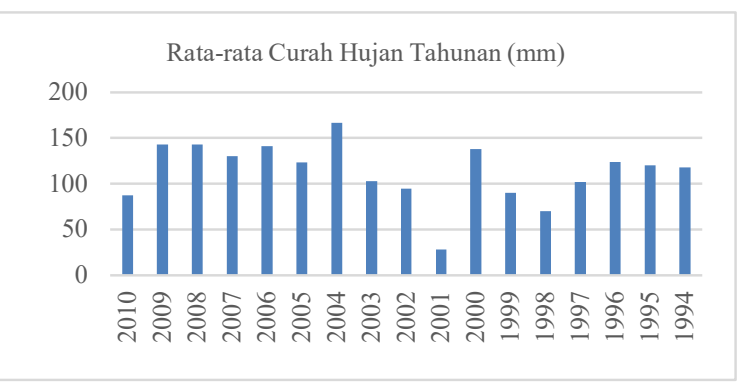

Gambar 5. Distribusi Curah hujan Tahunan

Tabel 3. Rekapitulasi Analisis Frekuensi Data Hujan

\begin{tabular}{|c|c|c|c|c|c|}
\hline \multirow{2}{*}{ Periode Ulang } & \multicolumn{5}{|c|}{ Analisa Frekuensi Curah Hujan Rencana (mm) } \\
\cline { 2 - 6 } & Normal & $\begin{array}{c}\text { Log Normal } \\
\text { 2 Paramater }\end{array}$ & Gumbell & Pearson III & $\begin{array}{c}\text { Log Pearson } \\
\text { III }\end{array}$ \\
\hline & & & & & \\
2 & 113.07 & 108.52 & 108.25 & 118.11 & 122.52 \\
5 & 140.89 & 138.44 & 144.30 & 130.39 & 143.58 \\
10 & 155.46 & 156.74 & 168.18 & 150.85 & 149.58 \\
25 & 167.38 & 177.55 & 198.34 & 155.44 & 150.07 \\
50 & 180.96 & 195.58 & 220.71 & 163.09 & 150.57 \\
100 & 190.23 & 211.48 & 242.92 & 170.41 & 150.73 \\
\hline
\end{tabular}


Dari hasil analisis frekuensi curah hujan seperti terlihat pada Tabel 3 di atas, dapat diambil kesimpulan sebagai berikut :

a. Untuk periode ulang 2 tahun, curah hujan yang diperoleh dengan menggunakan metode Log Pearson III memberikan hasil yang paling besar.

b.Untuk periode ulang 5, 10, 25, 50 dan 100 tahun, curah hujan yang diperoleh dengan menggunakan metode Gumbel memberikan hasil yang paling besar.

Pengujian sebaran dilakukan untuk menguji apakah sebaran yang dipilih cocok dengan sebaran empirisnya. Pengujian parameter dilakukan dengan menggunakan metode Smirnov-Kolmogorov (Mazur dkk., 2019). Dari hasil uji kecocokan menunjukkan bahwa yang paling mendekati kondisi di lapangan adalah dengan menggunakan metode distribusi Gumbel type I. Hal ini ditandai dengan nilai terkecil selisih maksimum antara hujan aktual dan hujan prediksi. Berdasarkan hasil perhitungan tersebut, metode analisis frekuensi curah hujan yang digunakan adalah metode Distribusi Gumbel.

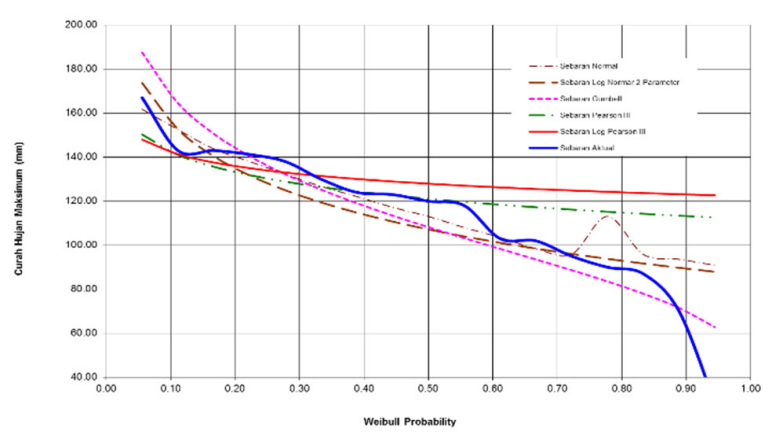

Gambar 6. Perbandingan Curah Hujan Harian rata-rata maksimum dan Prediksi

\section{Analisis coefisien pengaliran (C)}

Untuk memprediksi banjir rencana, diperlukan data daerah tangkapan antara lain : luas daerah tangkapan, penggunaan lahan, kemiringan saluran serta panjang saluran utama pada masing-masing sub DAS yang ditinjau.

Berdasarkan hasil interpretasi citra satelit TM 8 (2018) menggunakan metode NDVI (Putranto dkk., 2020), maka diperoleh klasifikasi penggunaan lahan dan interpretasi nilai coefisien infiltrasi menggunakan pedoman penilaian berdasarkan (Suripin, 2004) untuk masing-masing sub sistem sungai yang diprediksi akan mempengaruhi banjir rencana wilayah penelitian dapat diuraikan sebagai berikut :

\section{a. sungai Kungkilan}

Penggunaan lahan dan nilai koefisien pengaliran untuk saluran pengalihan sungai Kungkilan bagian hulu dengan luas daerah tangkapan seluas $1.783,54$ ha, diperoleh nilai koefisien pengaliran sebesar 0,29. Sementara nilai koefisien pengaliran untuk pembuatan saluran pengalihan sungai Kungkilan bagian hilir dengan luas daerah tangkapan air seluas 2.051,68 ha, diperoleh rata-rata nilai $\mathrm{C}$ sebesar 0,289 .

Tabel 4. Rekapitulasi Nilai C sungai Kungkilan Hulu dan Hilir

\begin{tabular}{|l|r|r|r|}
\hline \multicolumn{1}{|c|}{ Penggunaan lahan } & \multicolumn{1}{c|}{ Koef C } & \multicolumn{1}{c|}{ Luas (ha) } & Luas x koef C \\
\hline Padang & 0.35 & 277.85 & 97.25 \\
\hline Perkebunan Rakyat & 0.28 & 935.13 & 261.84 \\
\hline Hutan Belukar & 0.28 & 570.56 & 159.76 \\
\hline Jumlah & $1,783.54$ & 518.84 \\
\hline \multicolumn{3}{|c|}{ C sub DAS } & 0.29 \\
\hline \multicolumn{1}{|c|}{ Penggunaan lahan } & \multicolumn{1}{|c|}{ Koef C } & \multicolumn{1}{c|}{ Luas (ha) } & Luas x koef C \\
\hline Padang & 0.35 & 277.85 & 97.25 \\
\hline Perkebunan Rakyat & 0.28 & $1,203.27$ & 336.92 \\
\hline Hutan Belukar & 0.28 & 570.56 & 159.76 \\
\hline Jumlah & $2,051.68$ & 593.92 \\
\hline \multicolumn{3}{|c|}{ C sub DAS } & 0.289 \\
\hline
\end{tabular}

\section{b. Sungai Nipe}

Penggunaan lahan dan nilai koefisien pengaliran untuk pengalihan sungai Nipei Hulu dengan luasan sub DAS Nipei hulu 379,87 ha, nilai koefisien pengaliran sebesar 0,280. Sementara untuk pengalihan sungai sub DAS Nipei hilir dengan luasan 440,59 ha nilai koefisien pengaliran kumulatif sebesar 0,280 .

Tabel 5. Rekapitulasi Nilai C sungai Kungkilan Hulu dan Hilir

\begin{tabular}{|c|c|c|c|}
\hline Penggunaan lahan & Koef C & Luas (ha) & Luas $\mathrm{x}$ koef $\mathrm{C}$ \\
\hline Perkebunan Rakyat & 0.28 & 379.87 & 106.36 \\
\hline Jumlah & & 379.87 & 106.36 \\
\hline \multicolumn{3}{|c|}{ C sub DAS } & 0.280 \\
\hline Penggunaan lahan & Koef C & Luas (ha) & Luas $\mathrm{x}$ koef $\mathrm{C}$ \\
\hline Perkebunan Rakyat & 0.28 & 440.59 & 123.37 \\
\hline Jumlah & & 440.59 & 123.37 \\
\hline \multicolumn{3}{|c|}{ C sub DAS } & 0.280 \\
\hline
\end{tabular}

\section{c. Sungai Tabuhan}

Penggunaan lahan dan nilai koefisien pengaliran untuk pengalihan saluran pada sub DAS Tabuhan hulu dengan luas daerah tangkapan 114,73 ha, nilai koefisien pengaliran sebesar 0,340. Sementara pada sub sistem sungai Tabuhan bagian hilir, dengan luas daerah tangkapan air seluas 373,80 ha, nilai koefisien pengaliran sebesar 0,299.

Tabel 6. Rekapitulasi Nilai C sungai Tabuhan Hulu dan Hilir

\begin{tabular}{|c|c|c|c|}
\hline Penggunaan lahan & Koef C & Luas (ha) & Luas $\mathrm{x}$ koef $\mathrm{C}$ \\
\hline Tegalan/Ladang & 0.35 & 99.05 & 34.67 \\
\hline Perkebunan Rakyat & 0.28 & 15.68 & 4.39 \\
\hline Jumlah & & 114.73 & 39.06 \\
\hline \multicolumn{3}{|c|}{ C sub DAS } & 0.340 \\
\hline Penggunaan lahan & Koef C & Luas (ha) & Luas $\mathrm{x}$ koef $\mathrm{C}$ \\
\hline Tegalan/Ladang & 0.35 & 99.05 & 34.67 \\
\hline Perkebunan Rakyat & 0.28 & 248.88 & 69.69 \\
\hline Hutan Belukar & 0.28 & 25.87 & 7.24 \\
\hline Jumlah & & 373.80 & 111.60 \\
\hline \multicolumn{3}{|c|}{ C sub DAS } & 0.299 \\
\hline
\end{tabular}




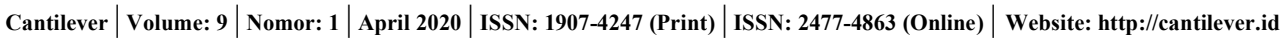

Dinar DA Putranto, dkk. / Analisis Profil Dasar Saluran Baru untuk Mengurangi Kecepatan Aliran pada Pengalihan Sungai

Analisis debit banjir

Penentuan debit banjir rencana, dilakukan dengan menggunakan metode Hidrograf Satuan Sintetis Nakayasu (Karamma \& Pallu, 2018).

Besarnya debit untuk barbagai periode ulang pada masing-masing sungai yang ditinjau dapat dilihat pada Gambar 7, yang menjelaskan rencana banjir untuk periode ulang hingga 100 tahun untuk masing-masing saluran pengalihan dari sungai yang direncanakan untuk dipindahkan.
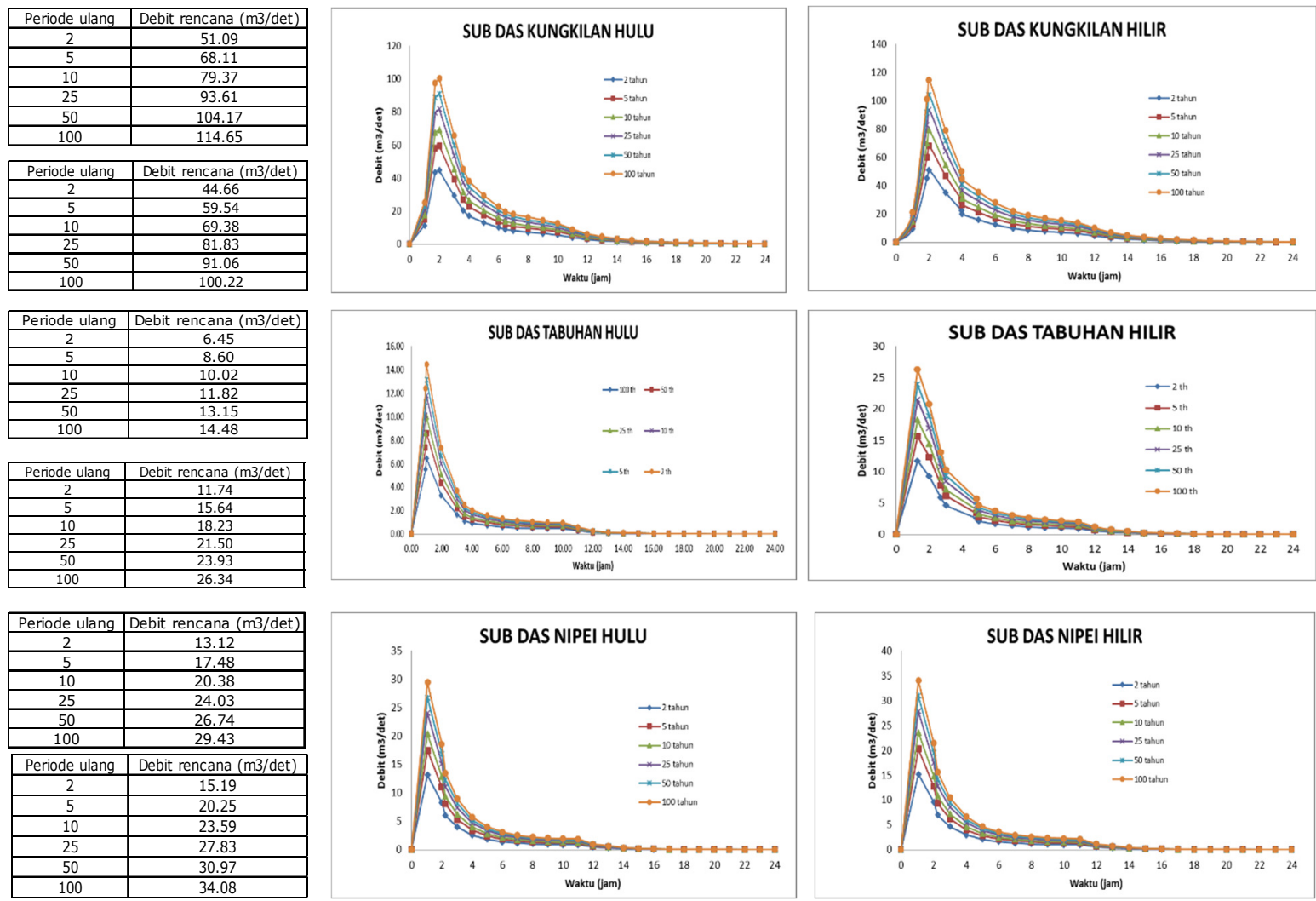

Gambar 7. Debit rencana dan HSS Nakayasu pada pengalihan saluran sungai Kungkilan, Tabuhan dan Nipei, bagian Hulu dan hilir

\section{Analisis dimensi saluran}

Perhitungan dimensi saluran menggunakan persamaan Manning (Putro \& Hadihardaja, 2013). Penetapan periode ulang didasarkan terhadap resiko yang nantinya dihadapi, untuk itu penetapan periode ulang untuk merancang dimensi ke 3 saluran tersebut ditetapkan 50 tahun. Berdasarkan debit rancangan periode 50 Tahun, diperoleh kecepatan aliran yang dihitung dengan menggunakan persamaan debit aliran, $V=\frac{\mathrm{Q}}{\mathrm{A}}$, nilai terkecil pada sungai Tabuhan hulu, sebesar $0,4 \mathrm{~m} /$ det. Berdasarkan debit terkecil pada sungai Tabuhan hulu tersebut, maka kecepatan minimum yang digunakan sebaiknya menggunakan dua kalinya 0.8 m/det (Sukarno dkk., 2019).

\section{a. Sungai Kungkilan}

Dari hasil analisis menggunakan, persamaan manning untuk saluran pengalihan sungai Kungkilan bagian hulu, digunakan lebar dasar saluran mengikuti kondisi existing yaitu b : $8 \mathrm{~m}$ dan $\mathrm{H}$ : $3.5 \mathrm{~m}$ dengan kemiringan tebing (horizontal : vertikal) adalah 1,5:1. Sementara untuk desain penampang melintang saluran baru sungai Kungkilan bagian hilir digunakan lebar dasar saluran mengikuti kondisi existing yaitu $b: 10 \mathrm{~m}$ dan $\mathrm{H}: 3.5 \mathrm{~m}$ dengan kemiringan tebing (horizontal : vertikal) adalah $1.5: 1$.

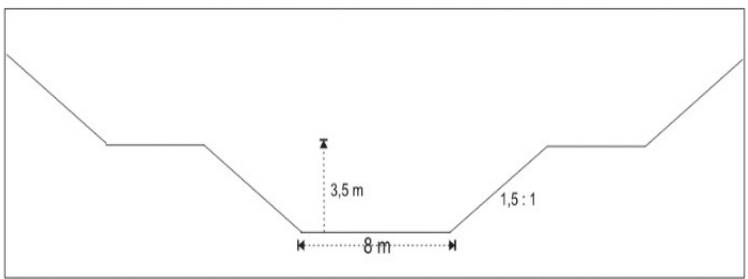

Gambar 8. Tipikal desain penampang melintang saluran baru sungai Kungkilan

Untuk menghindari terjadinya gerusan pada dasar saluran, maka kelandaian dasar saluran dibuat sangat landai yaitu dengan kemiringan sebesar $0,0005 \%$. Dengan kemiringan sebesar tersebut, maka saluran pengalihan sungai Kungkilan, dibuat 
trap, untuk setiap jarak $500 \mathrm{~m}$, dengan perbedaan elevasi sebesar $0,25 \mathrm{~m}$. Sementara perbedaan elevasi trap, dibuat sebesar $50 \mathrm{Cm}$ untuk sepanjang $50 \mathrm{~m}$. Dengan demikian untuk rencana normalisasi sungai Kungkilan dengan panjang sejauh $1.750 \mathrm{~m}$, dibuat dua kali trap, dengan jumlah trap masing-masing dua dan tiga trap pada tengah saluran (Gambar 9).

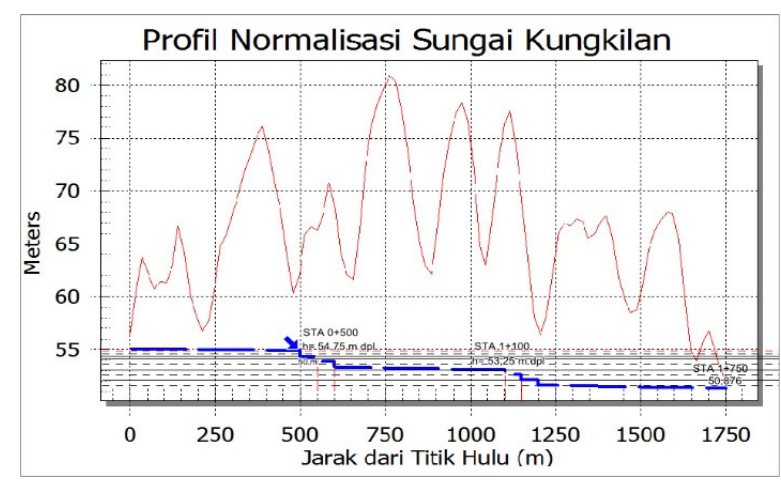

Gambar 9. Profil memanjang, rencana dasar saluran normalisasi sungai Kungkilan, digunakan model terasiring (trap)

Sebagai bagian dari penguatan hasil desain analisis penampang saluran yang telah dilakukan, perlu dilakukan pemodelan dengan menggunakan salah satu perangkat lunak yang sesuai. Dalam hal ini dengan memanfaatkan program HEC-RAS 4.1. Simulasi dengan mengambil parameter koefisien pembesaran dan penyempitan (expansion and construction coeffisien) alur sungai akibat kehilangan energi saat terjadi penyempitan dan pelebaran saluran $(\mathrm{Hc})$. Setiap ruas dihitung per STA 100 m, jika Hc hasilnya positif maka koefisien yang digunakan 0,1 , tapi jika hasilnya negatif maka digunakan 0,3 (Triatmodjo, 1993). Parameter yang digunakan dalam pemodelan HEC-RAS adalah geometri saluran alur sungai, tampang memanjang dan melintang, kekasaran dasar sungai (Coeffisien Manning), serta koefisien pembesaran dan penyempitan.

Hasil simulasi tanpa menggunakan trap pada pengalihan sungai Kungkilan, pada STA $1+200$ diperoleh nilai kecepatan sebesar $1,8 \mathrm{~m} / \mathrm{s}$ dan pada STA $0+600$ nilai kecepatan $1,85 \mathrm{~m} / \mathrm{s}$.

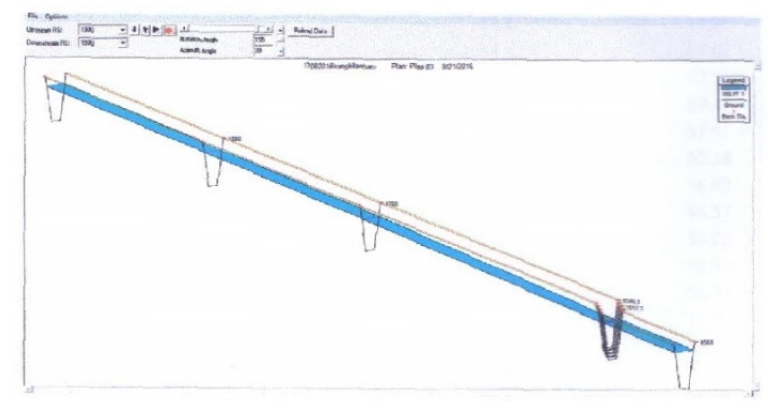

Gambar 10. Simulasi 3D HEC-RAS sungai Kungkilan tanpa menggunakan trap STA $1+500-$ STA $1+900$
Untuk mengurangi kecepatan aliran pada dasar saluran, maka sesuai hasil kajian telah dilakukan desain menggunakan trap pada dasar saluran. Dari hasil simulasi menggunakan HEC-RAS, menunjukkan bahwa pada trap pertama STA $1+549$, terjadi penurunan kecepatan dari $2,2 \mathrm{~m} / \mathrm{s}$ menjadi $1,37 \mathrm{~m} / \mathrm{s}$. Sementara pada trap kedua STA 0+958, terjadi penurunan kecepatan dari $2,61 \mathrm{~m} / \mathrm{s}$ menjadi $1,37 \mathrm{~m} / \mathrm{s}$ dan trap ketiga pada STA $0+358$, terjadi penurunan kecepatan dari $3,45 \mathrm{~m} / \mathrm{s}$ menjadi 1,56 $\mathrm{m} / \mathrm{s}$.

Dengan demikian telah dapat dibuktikan bahwa pembuatan desain dasar saluran dengan memanfaatkan sistem trap dapat mengurangi energi gerusan pada dasar saluran untuk meminimalkan terjadinya erosi dan sedimentasi yang berlebihan, mengingat perbedaan elevasi yang terlalu tinggi antara inlet dan outlet hasil pengalihan sungai.

Sementara itu desain dasar saluran dengan sistem trap, pada daerah tikungan, seperti STA $1+200$, perubahan kecepatan aliran dari $1,81 \mathrm{~m} / \mathrm{s}$ menjadi $1,64 \mathrm{~m} / \mathrm{s}$. Demikian juga pada tikungan STA 0+600, perubahan kecepatan aliran dari $1,85 \mathrm{~m} / \mathrm{s}$ menjadi $1,64 \mathrm{~m} / \mathrm{s}$. Sehingga dapat disimpulkan bahwa perubahan kecepatan tidak berlaku signifikan pada daerah tikungan.

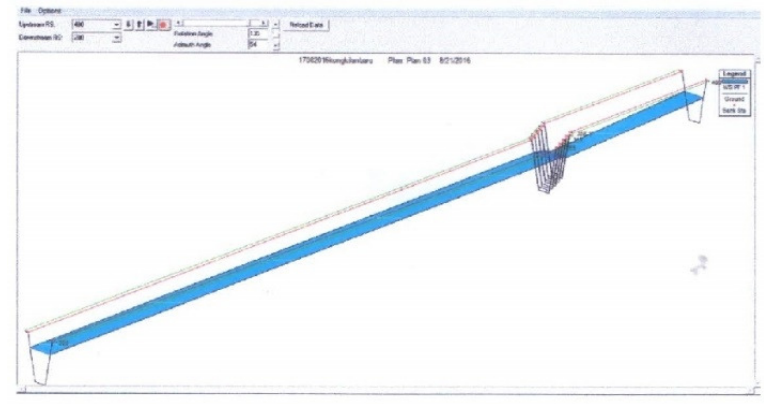

(a)

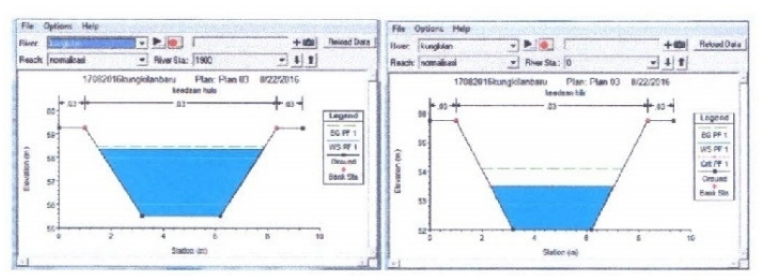

(b)

Gambar 11. Simulasi 3D saluran pengalihan sungai Kungkilan dengan menggunakan trap: (a) perubahan kecepatan aliran pada STA $1+500-$ STA $1+900$; (b) perubahan tinggi debit pada saluran

\section{b. Sungai Tabuhan}

Seperti halnya dengan sungai Kungkilan, maka desain penampang sungai Tabuhan, juga dibuat menggunakan trap, namun lebar penampang sungai berbeda. Dari hasil analisis didapatkan lebar dasar saluran untuk pengalihan bagian hulu mengikuti kondisi sungai existing yaitu $\mathrm{b}: 5 \mathrm{~m}$ dan $\mathrm{H}: 2.5 \mathrm{~m}$ dengan kemiringan tebing (horizontal : vertikal) 


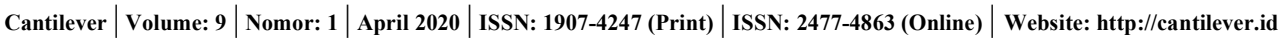

Dinar DA Putranto, dkk. / Analisis Profil Dasar Saluran Baru untuk Mengurangi Kecepatan Aliran pada Pengalihan Sungai

adalah $1.5: 1$. Sementara pada daerah hilir saluran baru lebar dasar saluran mengikuti kondisi existing yaitu $\mathrm{b}: 6 \mathrm{~m}$ dan $\mathrm{H}: 2.5 \mathrm{~m}$ dengan kemiringan tebing (horizontal : vertikal) adalah $1.5: 1$

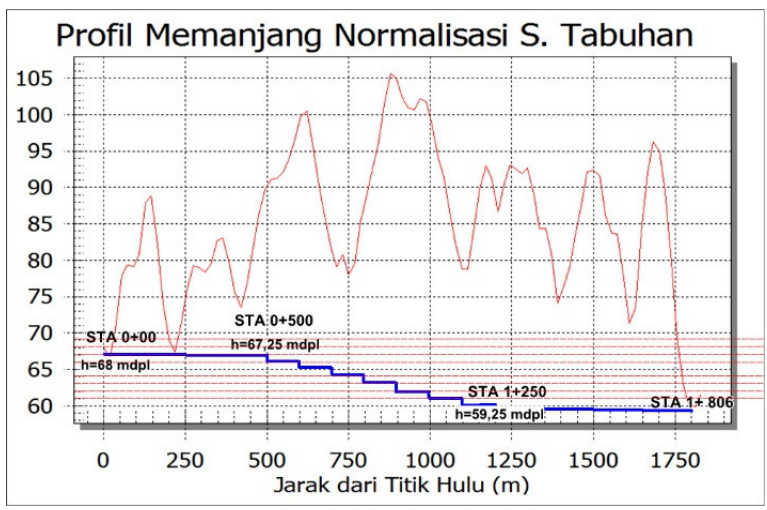

Gambar 12. Desain penampang memanjang saluran sungai Tabuhan

\section{c. Sungai Nipe}

Dari hasil analisis didapatkan lebar dasar rencana saluran baru bagian hulu dan hilir mengikuti kondisi existing yaitu $\mathrm{b}: 10 \mathrm{~m}$ dan $\mathrm{H}: 2.5 \mathrm{~m}$ dengan kemiringan tebing (horizontal : vertical) adalah 1.5 : 1 .
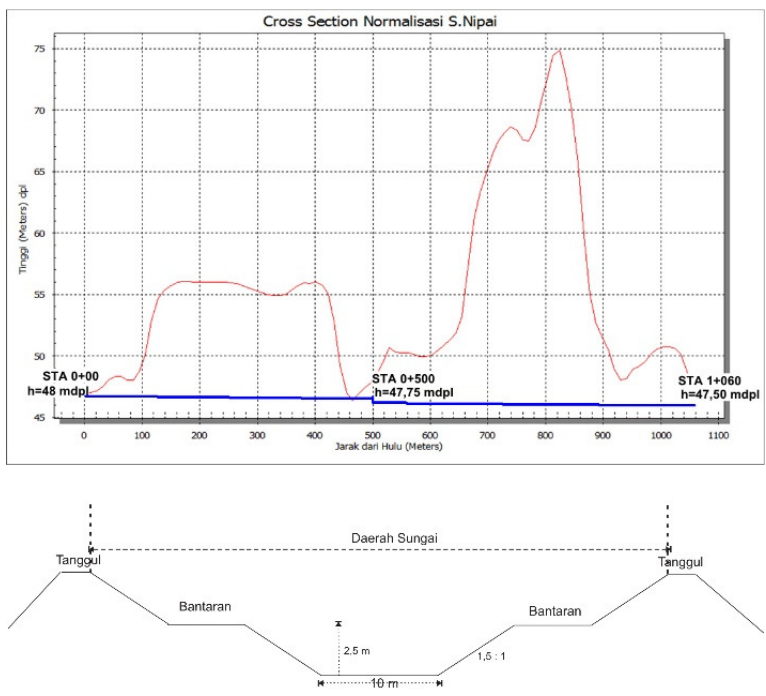

Gambar 13. Desain dasar saluran dan penampang melintang saluran baru sungai Nipei dibuat dengan profil ganda

Mengingat kemiringan semua sungai pengalihan sangat tinggi, agar gerusan di dasar saluran tidak terlalu besar maka kecepatan aliran harus dikurangi yaitu membuat saluran lebih landai dengan cara membuat bangunan trap di beberapa titik sepanjang saluran baru. Pada sungai yang perbedaan tinggi antara debit banjir dan debit minimumnya besar, pada waktu air rendah, alurnya sangat labil. Agar dapat diperoleh alur yang stabil, maka dalam rangka perbaikan dan pengaturan sungai, dibuat pembentukan profil ganda.

Dari seluruh profil saluran sungai pengalihan berdasarkan desain penampang dan debit saluran dengan analisis yang telah dibuat dan disimulasikan dengan menggunakan HEC-RAS, tidak ada air yang meluap hingga ke dataran banjir atau bahu saluran baru hasil rencana. Sehingga dapat disimpulkan, bahwa dengan desain rencana penampang saluran yang dialirkan menggunakan debit rancangan periode ulang 50 tahun, aman terhadap banjir.

\section{KESIMPULAN}

Berdasarkan hasil analisis dan bahasan yang telah dilakukan dengan menggunakan seluruh parameter DAS yang diperoleh langsung dilapangan maupun menggunakan beberapa data pendukung, maka dapat disimpulkan sebagai berikut :

a. Rancangan debit puncak tertinggi 50 tahunan adalah pada sungai Kungkilan sebesar 104,17 $\mathrm{m}^{3} / \mathrm{s}$ dan yang terendah untuk periode ulang 50 tahun adalah pada sungai Tabuhan hulu, sebesar $13,15 \mathrm{~m}^{3} / \mathrm{s}$

b. Hasil analisis profil muka banjir berdasarkan desain saluran yang telah dirancang untuk tiap saluran pengalihan sungai, menunjukkan bahwa dengan lebar dasar saluran untuk setiap saluran pengalihan sama dengan saluran asli, dan kedalaman saluran bervariasi, yaitu 3,5 m untuk sungai Kungkilan, $3 \mathrm{~m}$ untuk sungai Tabuhan dan 2 m untuk sungai Nipei, maka dengan debit rancangan untuk maksimum $104,17 \mathrm{~m}^{3} / \mathrm{s}$ periode ulang 50 tahun, ketinggian banjir masih belum terlampaui

c. Dengan desain dimensi saluran seperti kondisi dimensi sungai eksisting, dan kondisi perbedaan elevasi terlalu besar, maka pembentukan dasar saluran dengan sistem trap, untuk mengeliminir kecepatan aliran, telah merubah kecepatan aliran hampir $50 \%$ dari kecepatan awal, sebelum dasar saluran dimodifikasi.

\section{UCAPAN TERIMA KASIH}

Ucapan terima kasih disampaikan pada Lembaga Penelitian dan Pengabdian Kepada Masyarakat Universitas Sriwijaya yang telah memberikan dana penelitian Hibah Kompetitif Tahun 2016 bagi terlaksananya penelitian ini.

\section{REFERENSI}

Sukarno, D. E. T., Hendratta, L. A., \& Mangangka, I. R. (2019). Studi Pengalihan Alur Sungai Araren di Desa Pinasungkulan Kota Bitung. Jurnal Sipil Statik, 7(7), 835-846.

Karamma, R. \& Pallu, M. S. (2018). Comparison of Model Hidrograf Synthetic Units ( HSS ) with the Model of Hidrograf Observations on DAS Jeneberang Gowa 
Regency, Indonesia. International Journal of Innovative Science and Research Technology, 3(2), 617-623.

Kementerian PUPR. (2015). Pengalihan Alur Sungai Dan / Atau Pemanfaatan Ruas Bekas Sungai. Retrieved from http://sda.pu.go.id:8183/panduan/unduh-referensiperaturan/PERMEN PUPR 26 2015.pdf.

Kurniawan, N., Putranto, D. D. A., \& Sarino (2020). Water Management in The Primary Channel of Kumpeh Swamp Irrigation Area. International Journal of Scientific and Technology Research, 9(3), 3290-3295.

Mazur, R., Ryżak, M., Sochan, A., Marciszuk, K., Beczek, M., Lamorski, K., \& Bieganowski, A. (2020). Surface deformation and displacement of bed elements during splash - Model tests. Catena, 185. https://doi.org/10.1016/j.catena.2019.104277

Purwitaningsih, S. \& Pamungkas, A. (2017). Analisis Kondisi Hidrologi Daerah Aliran Sungai Kedurus untuk Mengurangi Banjir Menggunakan Model Hidrologi SWAT. Jurnal Teknik ITS, 6(2). https://doi.org/10.12962/j23373539.v6i2.24809.

Putranto, D. D. A., Fitriani, H., \& Andriani. (2020). Analysis of Carrying Capacity of Land for Special Economic Zones Tanjung Api-Api in Infrastructure Development. International Journal of Scientific and Technology Research, 9(2), 1248-1253.

Putranto, D. D. A., Sarino, \& Yuono, A. L. (2017). Spatial Distribution Level of Land Erosion Disposition Based on the Analysis of Slope on Central Lematang Sub Basin. AIP Conference Proceedings. https://doi.org/10.1063/1.5011626.

Putranto D. D. A, Yuono A. L, Sarino, \& Priatna S. J. (2015).
Model Medan Digital untuk Pemodelan Rainfall-Run-off Analisis Sedimentasi secara Regional pada DAS MUSI. Palembang. Indonesia: Lembaga Penelitian University of Sriwijaya.

Putro, H. \& Hadihardaja J. (2013). Variasi Koefisien Kekasaran Manning (n) pada Flume Akrilic pada Variasi Kemiringan Saluran dan Debit Aliran. Media Komunikasi Teknik Sipil, 19(2), 141-146.

Riswan \& Saismana, U. (2016). Sistem Pengendalian Air untuk Menambang Batubara di Bawah Aliran Sungai (Studi Kasus). Seminar Nasional Kebumian XI (pp. 60-65), UPN Veteran, Yogyakarta, 3-4 November 2016. https://doi.org/https://www.academia.edu/36016726/.

Sarino, S., Dinar D. A. P., Yuono, A. L., \& Juliana, I. C. (2019). Database Structure of Land Allocation Management Information System for Estimating Run-Off in Watersheds. International Journal of GEOMATE, 17(59), 34-42. https://doi.org/10.21660/2019.59.4710.

Suripin (2004). Sistem Drainase Perkotaan yang Berkelanjutan (3rd ed.). Yogyakarta: ANDI.

Triatmodjo, B. (1993). Hidraulika II, Yogyakarta: Beta Ofset.

Wilken, F., Baur, M., Sommer, M., Deumlich, D., Bens, O., \& Fiener, P. (2018). Uncertainties In Rainfall Kinetic Energy-Intensity Relations For Soil Erosion Modelling. Catena, 171, 234-244. https://doi.org/10.1016/j.catena.2018.07.002

Yuono, A. L., Putranto, D. D. A., \& Tukirun, S. (2020). Effect of Land Use Changes of Upstream Komering Sub Watershed on Declining Water Availability. Journal of Ecological Engineering, 21(2), 126-130. https://doi.org/10.12911/22998993/116331. 